\title{
LINGUISTIC INSIGHTS INTO THE READING PROCESS
}

\author{
Ronald Wardhaugh \\ University of Michigan
}

\begin{abstract}
Various linguists have put forward proposals for studying the reading process and for teaching reading. Bloomfield and Fries tried to use linguistic knowledge to devise a method of teaching reading based on a belief that children had to learn sound-symbol relationships in order to read. Venezky has proposed a model of the reading process which is something of a bridge between their work and that of Chomsky and Halle. The latter have proposed that present English orthography is an optimal system for the language and that the phonemes of so much interest to Bloomfield and Fries are no more than methodological artifacts. However, they acknowledge that their phonological model might not be an appropriate one for children. If this is the case, then certain insights from Bloomfield and Fries may still be relevant. The possible applications of linguistics to reading are still uncertain in the absence of empirical evidence to support any of the present hypotheses.
\end{abstract}

Within applied linguistics the topic of linguistics and reading is of great interest for several reasons which should be stated at the outset. ${ }^{1}$ First of all, it forces us to discuss some of the difficulties involved in attempts to use insights from research in theoretical linguistics in the solution of a practical problem, in this case the problem being one of teaching children to read and of understanding the reading process. In other cases the problem may be one of teaching a foreign language, of translating a text, or of choosing a national language. The same difficulties arise in each case: just what linguistic knowledge is relevant to solving the problem and how may knowledge which is considered relevant be used? The teaching of reading is a very real problem almost everywhere in the world and often a controversial one. Those linguists who have looked at it have adopted a variety of different approaches because they have viewed the nature of the problem differently and because they have also held different views about the proper nature of linguistic inquiry. In this paper, therefore, I will try to indicate some of the different views

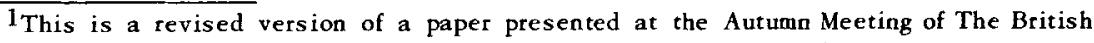
Association for Applied Linguistics, in Edinburgh on September 28, 1968.
} 
of the reading process held by different linguists and some of the solutions that they have proposed.

The second reason which makes this topic interesting is that it allows us to observe some of the limitations of linguistic knowledge in solving a practical problem. In the course of the paper, some indication will be given of specific areas in which the limits of linguistic knowledge are reached and in which other kinds of knowledge are called for. It is apparent that certain linguists have confused non-linguistic matters with linguistic ones, possibly to the extent of over-reaching themselves. Such over-reaching is not unique to linguists: experts from many disciplines are accustomed to speaking on topics outside their field of competence with the same air of authority they assume within that field!

The third reason is no less important than the first two: it is to show how linguistics itself is changing in its concerns, its techniques, and its rhetoric. This last statement should become clearer when the approaches to the reading process taken by Bloomfield and Fries are compared with those taken by Chomsky and Halle. There is a vast difference in both the content and the style of their discussions of the problem; however, there is some reason to say that the conclusions of Bloomfield and Fries on the one hand and those of Chomsky and Halle on the other may not actually be so very far apart.

The earliest proposals to use modern linguistic knowledge in the teaching of reading apparently came from Leonard Bloomfield, who was disturbed by certain aspects of school instruction, particularly the instruction given in language and in reading. For example, in a statement published in the very first volume of Language in 1925 explaining in part why the Linguistic Society of America had been founded, he wrote as follows:

Our schools are conducted by persons who, from professors of education down to teachers in the classroom, know nothing of the results of linguistic science, not even the relation of writing to speech or of standard language to dialect. In short, they do not know what language is, and yet must teach it, and in consequence waste years of every child's life and reach a poor result. ${ }^{2}$

Bloomfield felt that the methods being used to teach his son to read were unenlightened and revealed a lack of knowledge about language. Consequently, he devised his own method of teaching his son to read and shared his opinions, methods, and materials

\footnotetext{
2Leonard Bloomfield, "Why a Linguistic Society?" Language, I (1925), p. 5.
} 
with those of his friends who had like interests. These later became known as the Bloomfield system for teaching reading when they found their way into Let's Read. ${ }^{3}$

Bloomfield rejected the "code-breaking" approach known as phonics as a way of teaching reading, claiming that the proponents of phonics confused statements about speech with those about writing to the point that they often appeared to be teaching children to speak, whereas all they were really doing was teaching them to associate written symbols with already known words. He objected to practices such as breaking up words into smaller parts corresponding to letters, crediting individual letters with having sounds; sounding out words (e.g., cat as $\left[\mathrm{k}^{\partial} æ \mathrm{t}^{\partial}\right]$ ), and blending sounds in an attempt to decode written words. Not only did Bloomfield reject a "code-breaking" or phonics approach, but he also rejected the competing "whole-word" approach, claiming that it ignored the alphabetic nature of the English writing system in that it treated English as though it were Chinese.

Bloomfield believed that children learning to read should first be trained in visual discrimination and then be taught to associate visually discriminated objects (letter and word shapes) to already known sounds and meanings. The story line (the meaning of the reading materials) was, he believed, far less important than the regularity of the connection between sounds and symbols, the phoneme-grapheme correspondences. In order therefore to guarantee that children should easily acquire a mastery of these correspondences, Bloomfield insisted that they be trained to discriminate in a left-to-right direction and also to name the letters of the alphabet without error. He believed that requiring children to name the letters in new words from left to right guaranteed both visual discrimination and correct word attack. Just as linguists, and presumably children (intuitively in their case), could segment an utterance into phonemes, beginning readers had to learn to segment words into graphemes, and the teacher systematically had to teach children to relate the two discrimination abilities. The Bloomfield approach is, therefore, one which is based on the introduction of regular sound-symbol, or phonemegrapheme, correspondences so that children can acquire the fundamental understanding they must acquire in order to read, the understanding that writing is a representation of speech, and, on the whole, quite a systematic one.

Bloomfield was also concerned with the notion of contrast, seeing a need to teach whole written words such as can, van, and

${ }^{3}$ Leonard Bloomfie Id and Clarence L. Barnhart, Let's Read (Detroit: Wayne State University Press, 1961). 
fan in contrast with each other and to introduce all the contrastive details of the English writing system gradually and systematically, so that the child learning to read would realize, as Bloomfield wrote, that "printed letter = speech sound to be spoken." 4 It is not surprising therefore that the resulting lists, exercises, and testing materials look something like the old "word family" lists in many of the old-fashioned nineteenth century readers. Here is an example of some testing materials from Let's Read:

$$
\begin{aligned}
& \text { ban, can, Dan, fan, gan, ... } \\
& \text { bat, cat, fat, gat, hat, ... } \\
& \text { bad, cad, dad, fad, gad, } \ldots \\
& \text { bap, cap, dap, gap, Hap, ... } \\
& \text { bag, cag, dag, fag, gag, ... }
\end{aligned}
$$

According to Bloomfield, the basic task the child learning to read had to master was that of understanding the spelling system of English not that of understanding the meanings of English words and sentences. Therefore, it was quite possible for teachers to use nonsense syllables and nonsense words in order to allow their students to achieve such mastery. He wrote as follows on this point:

Tell the child that the nonsense syllables are parts of real words which he will find in the books that he reads. For example, the child will know han in handle and jan in January and mag in magnet or magpie. The acquisition of nonsense syllables is an important part of the task of mastering the reading process. ${ }^{6}$

Later, Robert Hall, gave very much the same kind of advice, claiming that the "ultimate test of any method of teaching reading is whether the learners can deal with nonsense syllables. . ..,7 Both Bloomfield and Hall are really advocating an emphasis on a "code-breaking" approach, but not the particular "code-breaking" approach known as phonics. In his work, Bloomfield was concerned almost exclusively with monosyllabic words and polysyllabic words received very little attention. In defense of this emphasis, he claimed that his son found no difficulty in transferring to polysyllabic words once he had achieved a mastery of the monosyllabic patterns. This observation is a very interesting observation to which I shall have further occasion to refer in connection with the work of contemporary linguists.

\footnotetext{
${ }^{4}$ Bloomfield and Barnhart, p. 36.

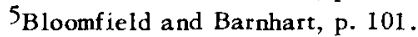

${ }^{6}$ Bloomfield and Barnhart, PP. 41-42.

${ }^{7}$ Robert A. Hall, Jr., Introductory Linguistics (Philadelphia: Chilton Company, 1964), p. 432.
} 
Believing that the major task the beginning reader must master is one wholly concerned with the interpretation of words and not one concerned with guessing at the meanings of words by using accompanying illustrations, Bloomfield rejected the use of illustrations in reading materials on the grounds that they are either irrelevant or misleading. Some of the materials for teaching reading that Fries and his followers were to develop following Bloomfield's example likewise do not contain pictures so that children may be left free to focus their attention on the words themselves rather than on the illustrations accompanying the words. The results of applying Bloomfield's theories to reading are reading materials like the following.
A rap. A gap.
Dad had a map.
Pat had a bat.
Tad had a tan cap.
Nan had a tan hat.
Nan had a fat cat.
A fat cat ran at a bad rat. ${ }^{8}$

There is much that is admirable in Bloomfield's ideas on reading. First of all, his work on English phoneme-grapheme correspondences was based on a good knowledge of the important surface phonological contrasts in English. Bloomfield also stressed the fact that the English writing system is basically an alphabetical one and that it is not as inconsistent as it is often made out to be, particularly when it is approached from the viewpoint of how sounds are represented in writing and not from that of how letters are pronounced, or, even worse, should be pronounced. Then, too, there is in his work on reading a welcome insistence that the proper content of reading and the basic insights necessary to understand the reading process are to be found in linguis tic rather than in social and psychological factors. However, the Bloomfield method has much more to say about the linguistic content of reading materials than about an actual method of teaching reading. What comments on methodology there are in Bloomfield's writings seem to be based on an extrapolation of some procedures, such as contrast, which linguists have found useful in their work as linguists, and not on procedures derived from teaching reading. This type of extrapolation is characteristic of much work in applied linguistics in general. It is certainly not

\footnotetext{
${ }^{8}$ Leonard Bloomfield and Chatence L. Barnhart, Let's Read, Part I (Experimental Edition) (Bronxville, N.Y.: C. L. Barnhart, Inc., 1963), p. 37.
} 
unique to the problem of using linguistic insights in understanding the reading process or in the teaching of reading!

A more recent proposal than Bloomfield's to use linguistic insights in reading was made by Charles Fries in Linguistics and Reading, ${ }^{9}$ undoubtedly the most influential book on linguistics and reading published to date. Like Bloomfield, Fries took the position that reading experts are quite unfamiliar with linguistics and in general exhibit little knowledge of language at all; consequently, he set out to correct this defect and to offer an outline of a method for teaching reading that drew heavily on linguistic insights in a manner reminiscent of the approach behind his well-known book on second language teaching, Teaching and Learning English as a Foreign Language. 10

One important distinction that Fries insisted on is in the use of the terms phonics, phonemics, and phonetics, and a whole chapter in his book is devoted to the problem of clarifying the differences among these terms and setting the record straight. The chapter contains example after example of the confused use of the three terms in the literature on reading and is a telling indictment of most writing on the subject of phonics, that is most writing on the "code-breaking" view of reading. Like Bloomfield before him, Fries emphasized that written English is alphabetic in nature and that English spelling is not inconsistent if statements about speech and statements about writing are clearly distinguished and if letters (graphemes) are regarded as representations of significant speech sounds (phonemes). Fries pointed out the regular spelling patterns in English and said that it was the reading teacher's task to teach these to beginning readers by presenting them in carefully arranged sequences and by giving beginning readers considerable practice in recognizing them in contrasting words.

Fries considered that in learning to read, children had to master a new visual task, in which they had to associate quite automatically visual responses with previously discriminated auditory responses. He believed that this process, which he regarded as a transfer process, required visual training, for example training in left-to-right eye movements and in the discrimination of the important features of letters and words. For this reason Fries rejected the concurrent introduction of both upper and lower case letters in beginning texts in favor of the exclusive use of

\footnotetext{
9 Charles C. Fries, Linguistirs and Reading (New York: Holt, Rinehart and Winston, Inc., 1963).

10 Charles C. Fries, Teaching and Learning English as a Foreign Language (Ann Arbor: University of Michigan Press, 1945).
} 
upper case letters so as to reduce the burden of discrimination for the child who was learning to read. He apparently rejected the argument that the elimination of ascenders and descenders and the resultant uniform "block" shapes of written words might result in the loss of many useful visual clues and would reduce the amount of visual information available to the child. Instead, Fries believed that children would find written words composed out of twenty-six uniform letters easier to perceive than the corresponding words composed out of twice that number of letters. Later he modified this view.

Fries also insisted on the use of contrastive word patterns since for him the principle of contrast was basic to both linguistic structure and visual perception. He rejected the spelling out of words that Bloomfield recommended, insisting instead that the critically important skill for children to acquire is one of being able to make visual discriminations between whole words and between whole patterns or units of meaning. He sought, therefore, to minimize any factor which would tend to require children to focus on units smaller than whole words. Although Fries recognized that written English is alphabetic and the alphabet is a contrastive system, he claimed that the more important system of contrasts was the one associated with words and meanings; consequently, his method was essentially a "whole-word" method rather than a "phonics" method of the traditional kind. Fries also stressed the importance of oral reading in the belief that the written message is but a representation of the oral message; however, his goal was still most definitely silent reading in the later stages of the program. The following is an example of a page from one of the Fries readers, as these were later developed from his ideas.

\author{
The Cat on the Van. \\ Dan is on the van. \\ Nat is on the van. \\ The pan is on the van. \\ The cat can bat the pan. \\ Dan can pat the cat. \\ The man ran the van. 11
}

Like Bloomfield, Fries had very little to say about comprehension: both apparently regarded comprehension as a basically passive activity which is highly dependent on oral language skills.

\footnotetext{
11 Charles C. Fries, Agnes C. Fries, Rosemary G. Wilson, and Mildred K. Rudolph, Merrill Linguistic Readers, Reader I (Columbus: Charles E. Merrill Books, Inc., 1966), p. 36.
} 
Children must learn to react instantly to the contrasts between mat and mate and between bit and beat. They already react to the differences between these words when they are spoken. What they must do in learning to read is to associate a visual pattern which they have learned to discriminate from other visual patterns to a speech pattern which they already know and can discriminate from other speech patterns. A child who is learning to read is already subconsciously aware of the different kinds of meanings and patterns in his language or he could not communicate in that language. What he needs to have unlocked for him is the code that is writing, so that he can have access to these different kinds of meanings and patterns through the medium of print. Fries went so far as to claim that this code can be unlocked for the beginning reader within a year of his learning to "talk satisfactorily," an age which he put at four or five. Needless to say, this claim has appeared to be rather extravagant to many who actually teach reading. Fries, therefore, did not regard the problem of teaching reading comprehension as a serious one. He obviously took issue with wide-ranging definitions of the reading process which relate that process to social, psychological, and physiological factors in favor of a view of the reading process as a kind of high-speed visual recognition of meanings that are already familiar to the reader. Reading comprehension is, therefore, a specific instance of general linguistic comprehension.

In both the Bloomfield and Fries approaches there is a strong insistence that a particular kind of linguistic knowledge is of paramount importance in gaining insight into the reading process and in determining the content of a reading series. There is also an assumption that principles of linguistic analysis, such as patterning and contrast, can by extrapolation become useful principles in reading pedagogy. Henry Lee Smith has pointed out 12 that there are certain valid pedagogical points which linguists have tended to ignore when they have talked about reading. In listing a number of these, he specifies such matters as typography, choice of illustrations, some repetition of patterns and words, and attention to both story line and characters. Smith cautions that it would be unwise for linguists who take an interest in reading to assume that reading teachers have learned nothing about teaching reading from their experiences, either individually or collectively. His words have been heeded to some extent in recent writings on linguistics and reading. They were obviously motivated in part by the hostility which characterized some of the

12Henry Lee Smith, "Review of Let's Read," Language, 39 (1963), pp. 67-78. 
original linguistics-reading discussions. That such hostility, particularly on the part of the reading experts, should have been aroused is not surprising when one reads some of the statements made by linguists about reading. For example, the statements by Bloomfield and Hall that there should be no illustrations in reading texts and the one by Fries that reading is a passive activity run counter to what most authorities on reading consider to be pedagogically sound observations. It must be emphasized that linguistics as a discipline has nothing at all to contribute to the discussion of whether or not there should be illustrations in a reading text: the inclusion or exclusion of illustrations is entirely a pedagogical decision. Likewise, any definition of reading which makes it out to be a passive activity indicates a certain lack of awareness of the many problems inherent in the teaching of reading.

It would not be unfair to say that what has become known as the linguistic method of teaching reading in North America is one which relies heavily on the work of Bloomfield and Fries. In essence, the method entails little more than the presentation of regular phoneme-grapheme, or sound-spelling, relationships in beginning reading texts, in many ways a kind of neo-phonics. The materials developed by the followers of Bloomfield and Fries reflect this concern: there is almost no indication in these materials that the possible linguistic contribution to reading involves anything more than the systematic introduction of the regularities and irregularities of English spelling. There is, in fact, scarcely more than an occasional passing reference to any other than this one solitary point that linguists have made about English.

The concern for phoneme-grapheme correspondences and for the importance of these in teaching reading has led to many studies, some quite sophisticated, of the relationships of various phonological segments to various graphological segments. These studies vary in quality and purpose. One of the best studies has come from Richard Venezky, particularly because he has attempted to relate his correspondence studies to a model of the reading process. ${ }^{13}$ Venezky has done more than count phonemes and graphemes, compute frequencies of correspondence, and attempt to program a logical sequence of correspondences. Rather, he has attempted to construct a set of rules for translating orthographic symbols into speech sounds, because he consider it useful to characterize the reading process in those terms. His work is, therefore, an attempt to construct a model of the reading

${ }^{13}$ Richard L. Venezky, "English Orthography: Its Graphical Structure and its Relation to Sound," Reading Research Quarterly, 2:3 (1967), pp. 75-105. 
process which recognizes the distributions of phonemes and graphemes, the frequencies of occurrence, and the patterns of correspondences. Central to the model is a set of rules which relates all of these. Venezky writes of the process of learning to read as follows:

Learning to read... requires primarily the translation from written symbols to sound, a procedure which is the basis of the reading process and is probably the only language skill unique to reading $\ldots \ldots \ldots \ldots \ldots \ldots \ldots \ldots \ldots \ldots \ldots$ The patterns summarized here represent an ideal system for translating from spelling to sound. . . 14

He describes how the model works as follows:

As examples of how this model organizes spelling-to-sound rules, the processes for predicting the pronunciation of social and signing are shown below.

social would be mapped into //sosrael// by the grapheme-to-morphophoneme rules for the separate units $s, o$, $c, i, a, l$. On the first morphophonemic level, the main word stress would be placed on the first syllable, resulting in //sósræel//. Then, through vowel reduction, //xæl// would become $/ / \mathrm{jol} / /$ and the resulting $/ / \mathrm{sj} / /$ would be palatalized to $/ / \$ / /$. The form //sóšel// would then be mapped onto the phonemic level, giving / sóšəl/.

signing would first be broken into sign and ing and then each of these graphemic allomorphs would be mapped onto the morphophonemic level, yielding //srgn// and //rng //. Upon combination of the two forms and the application of stress and certain phonotactical rules, the form //sígning// would result. By rules for leveling consonant clusters, final $/ / \mathrm{gg} / /$ would become $/ / \mathrm{g} / /$ and $/ / \mathrm{gn} / /$ would become $/ / \mathrm{n} / /$ with compensatory alternation of $/ / \mathrm{x} / /$ to $/ / \mathrm{ar} / /$. These operations yield //sámin// which is automatically mapped into / sáming $/ .15$

There are some very interesting differences between such an approach and that of Bloomfield and Fries. First of all, there is a concern with a level of representation called morphophonemic, a representation which looks very like the standard orthography. Then there is a set of ordered rules which, for example, assign stress and convert morphophonemes sometimes into morphophonemes but always eventually into phonemes. This last phonemic level is important in Venezky's work. He makes no attempt to

14Venezky, p. 102.

15 Venezky, pp. 94-95. 
eliminate it. Nor are the conversion rules necessarily made to conform to the demands of the kind of evaluation measure that the generative-transformationalists insist on in their work. In the signing example, the morphophoneme $/ / \mathrm{l} / /$ become the phonemes/ai/ (through an intermediate morphophonemic stage) in an apparently idiosyncratic way that a computer can handle which is apparently unrelated to the way in which certain other morphophonemes are given their phonemic realizations. However, Venezky's work does recognize some important patterns of English orthography as, for example, in the following comment on the $a$ grapheme and on the possible pedagogical consequences. Venezky points out that the letter $a$ has two primary pronunciations in stressed position, $/ x /$ and $/ \mathrm{e} /$, and he notes the orthographic and phonological relationships of pairs of words like annal and anal, rat and rate, and sane and sanity. He adds this comment:

The Bloomfieldian sequencing begins with the /a/ pronunciation for $a$, introducing the /e/ pronunciation at a later time with no special emphasis on the relation between /a/ and /e/ when derived from a. An alternative to this approach is to present both pronunciations at once, working with such pairs as rat:rate, mat:mate, fat:fate, hat:hate, and man:mane. Both the associations of $a$ to $/ æ /$ and $a$ to $/ \mathrm{e} /$ and the discrimination of the graphemic environments would be emphasized. Whether or not a child first learning to read can handle this task probably depends upon the pedagogy employed. The potential generalization derived from the differentiation approach, however, certainly is greater than that from the simple-sequence method. 16

Venezky has added a further dimension to understanding the reading process beyond that of the contributions of Bloomfield and Fries. As is indicated in Diagram I, Bloomfield and Fries were concerned with a model of the process in which the beginning reader was required to establish a set of visual contrasts and then to associate this set of visual contrasts to a set of already known phonemic contrasts. Venezky is less concerned with such simple sets of contrasts and associations. As indicated in Diagram II, he favors drawing up a set of conversion rules rather than a set of association rules. Moreover, he is very much concerned with proceeding from writing to speech rather than in the opposite direction.

In addition to postulating such a model of the process, Venezky also points out the way in which pairs of lax and tense, or, in his terms, "checked" and "free," vowels relate to each other in English, in such words pairs as fat:fate, met:mete, sit:site,

IGVenezky, p. 103 . 
Bloomfield and Fries
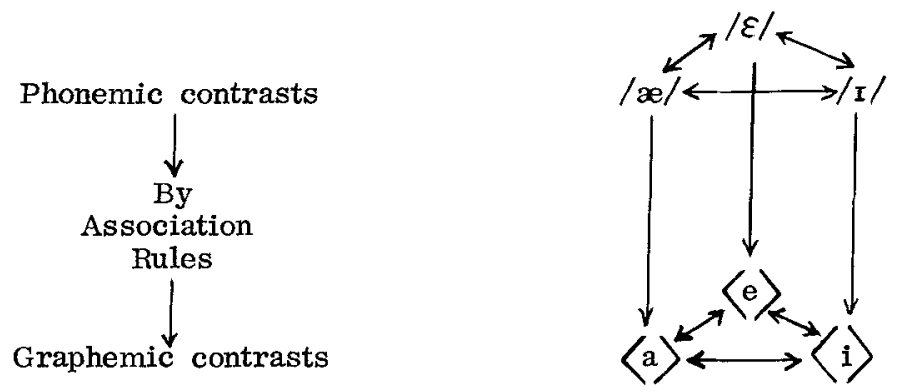

Diagram I

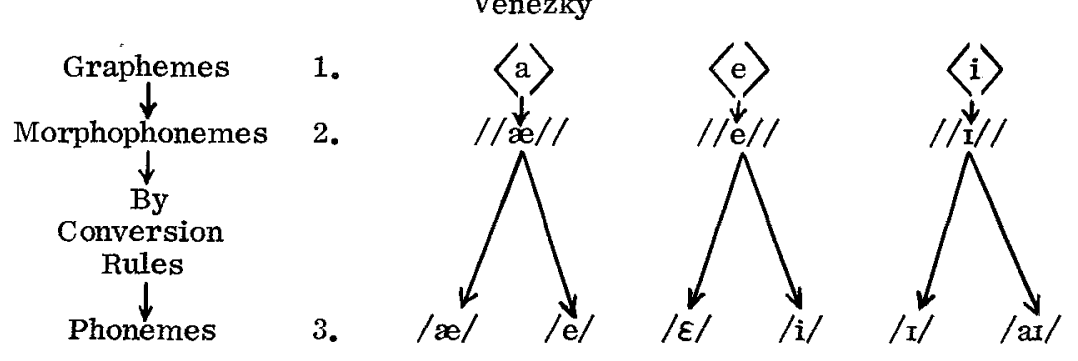

Example

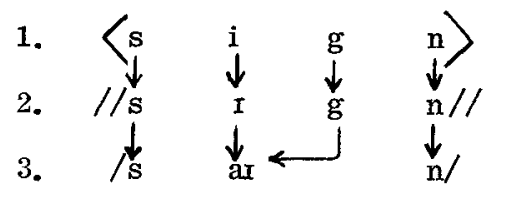

Diagram II

rob:robe, and mun:rune. He stresses the fact that English orthographic conventions require the use of the same vowel letter in certain orthographic patterns, as with the $a$ in sane:sanity, the $e$ in concede:concession, and the $i$ in collide:collision, but he makes no attempt to account for the patterning synchronically.

As is well known the phonemic level of representation of so much interest to Bloomfield, Fries, and Venezky, holds no attraction to Noam Chomsky and Morris Halle who regard it as no more than the methodological artifact of a particular kind of linguistic inquiry which they have attacked repeatedly. Chomsky and Halle favor a level of representation which they call systematic 
phonemic, a level which they claim the standard orthography captures quite well. They write as follows on this point in The Sound Pattern of English:

There is, incidentally, nothing particularly surprising about the fact that conventional orthography is . . . a near optimal system for the lexical representation of English words. The fundamental principle of orthography is that phonetic variation is not indicated where it is predictable by general rule. Thus, stress placement and regular vowel or consonant alternations are generally not reflected. Orthography is a system designed for readers who know the language, who understand sentences and therefore know the surface structure of sentences. Such readers can produce the correct phonetic forms, given the orthographic representation and the surface structure, by means of the rules that they employ in producing and interpreting speech. It would be quite pointless for the orthography to indicate these predictable variants. Except for unpredictable variants (e.g., man-men, buy-bought), an optimal orthography would have one representation for each lexical entry. Up to ambiguity, then, such a system would maintain a close correspondence between semantic units and orthographic representations. 17

According to this claim, therefore, English orthography is a good orthography for a speaker who "knows" the language. Chomsky and Halle proceed to describe the reading process in the following terms. Diagram III attempts to model what they say.

[The] process of reading aloud .... might ... be described in the following way. We assume a reader who has internalized a grammar $G$ of the language that he speaks natively. The reader is presented with a linear stretch $W$ of written symbols, in a conventional orthography. He produces as an internal representation of this linear stretch $W$ a string $S$ of abstract symbols of the sort that we have been considering. Utilizing the syntactic and semantic information available to him, from a preliminary analysis of $S$, as well as much extra-linguistic information regarding the writer and the context, the reader understands the utterance, and, in particular, assigns to $S$ a surface structure $\Sigma$. With $\Sigma$ available, he can then produce the phonetic representation of $S$ and, finally, the physical signal corresponding to the visual input $W$. Clearly, reading will be facilitated to the extent that the orthography used for $W$ corresponds to the underlying representations provided by the grammar $G$. To the extent that these correspond, the reader can rely on the familiar phonological processes to relate the visual input $W$ to an acoustic signal. Thus one would expect that conventional orthography

17 Noam Chomsky and Morris Halle, The Sound Pattern of English (New York: Harper \& Row, 1968), p. 49. 
should, by and large, be superior to phonemic transcription, which is in general quite remote from underlying lexical or phonological representation and not related to it by any linguistically significant set of rules.... [Conventional orthography] can be read only when the surface structure (including the internal structure of words) is known, that is, when the utterance is to some degree understood. 18

\section{Chomsky and Halle}

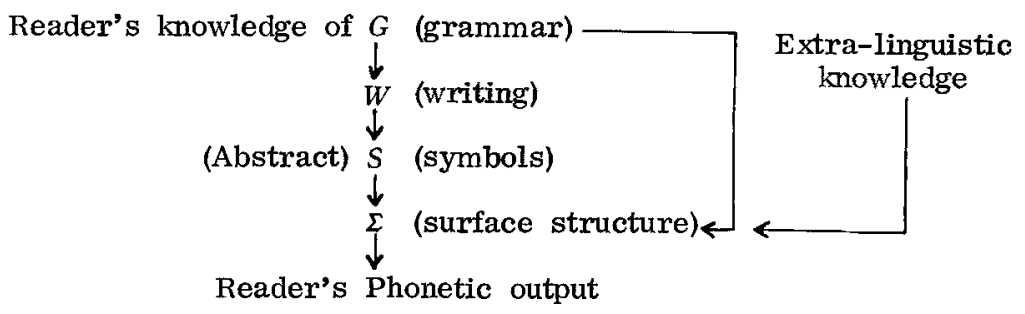

Diagram III

The Sound Pattern of English is primarily concerned with two problems. The first is the search for the optimal set of abstract phonological units to represent meaning units, that is for the best set of underlying lexical representations for English. The second is the search for the optimal set of rules to realize these lexical representations as phonetic output in order to convert a level of systematic phonemics into one of systematic phonetics. The resulf of the first search is the postulation of a set of systematic phonemes which look remarkably like the set of phonemes one needs to postulate for Early Modern English. For example, the set of systematic vowel phonemes contains only monophthongal representations and uses both tense and lax and round and unround as distinctive features. The symbolization used by Chomsky and Halle looks very much the same as that of standard English orthography and neatly draws together both phonetically quite different vowels, such as those in deduce and deduction, Canada and Canadian, and divine and divinity, and variant pronunciations such as the well-known variant pronunciations of ration, level, sinecure, and progress. The result of the search for the optimal set of phonological units or systematic phonemes is an extremely elegant and attractive system. The result of the second search for generative phonological rules is the postulation of a set of such rules which resemble, even in their clothing in distinctive features

18 Chomsky and Halle, pp. 49-50. 
and a generative phonology, that set of rules more traditionallyminded linguists must postulate to account for such phenomena as the Great Vowel Shift and other well-known sound changes. The Sound Pattern of English is a rather convincing demonstration that it is possible to describe a vast amount of English phonology within the system the authors postulate. The demonstration of the importance of two types of cluster, strong and weak, in determining stress placement, the generality of the transformational rules, and the importance of ordering and cycling in the application of the rules are undoubtedly important contributions to linguistic theory. However, there are many ad hoc decisions and exceptions and certainly the main vocabulary discussed in The Sound Pattern of English is of Romance origin. Moreover, the authors make few claims either for the truth of the system, stating only that The Sound Paltern of English is a report on "work in progress," 19 or for its psychological reality. The interesting question to ask oneself then is of what use is the system for understanding the processes involved in reading, and in particular in beginning reading.

It is possible to make some observations about the proposals put forward by Chomsky and Halle. The first one is that this type of theoretical work may really be of little or no use for gaining any insights at all into the reading process. One might observe that since Chomsky and Halle are largely concerned with vocabulary of Romance origin, what they have to say about such vocabulary adds little to any understanding of the processes involved in beginning reading. A beginning reader neither knows nor needs to know this vocabulary, and he certainly should not be taught it as part of the task of learning to read. His reading materials should be filled with vocabulary of Germanic origin, possibly of a simple monosyllabic variety. Certainly, it should not be words like policy, politic, politicize, politico-economic, polyandrous, polyandry, polygamous, polygamy, polyhedral, polyhedrous, pond, Pontiac, pontificate, and so on, which is one randomly selected sequence from the World Index to The Sound Pattern of English. ${ }^{20}$ It is an interesting fact that most of us can pronounce these words correctly without even knowing what some of them mean, but they are, except for pond, not the words we would expect a six-year old to know or want him to read. Rather they are just the words we expect him to be able to read later when, as a result of learning to read, he is in the position of

${ }^{19}$ Chomsky and Halle, p. vii.

${ }^{20}$ Chomsky and Halle, p. 458. 
being able to read in order to learn. Much of Comsky and Halle's description is valid only for a particular kind of person, a highly literate one. The crucial question is how much of such a rich system of phonology as that postulated in The Sound Pattern of English can we ascribe to a six-year old. Undoubtedly we must ascribe a great deal, for certainly a six-year old can assign stress correctly, does reduce vowels automatically, and does make the majority of surface phonetic contrasts without difficulty. A six-year old undoubtedly possesses much of the basic phonological competence he will have as an adult. At the same time though, it is likely that the sets of transformational rules that he uses and of lexical representations that he has at his disposal are more limited than the sets discussed in The Sound Pattern of English.

A second observation about the system concerns what may be called its direction. The system put forward in The Sound Pattern of English is one which appears to focus on how meaning is encoded into sound, in spite of the claims to neutrality between speaker and hearer which Chomsky has made repeatedly. For example, Chomsky and Halle point out that an awareness of surface structure is necessary if one is to assign certain stress patterns correctly and to make the rules operate properly in the production of sentences. However, the task which confronts a reader is one of decoding print to discover meaning. His task is one of somehow getting to meaning through print. The beginning reader must use the visual cues he has on the page to reconstruct the meaning, must somehow give a syntactic reading to a phrase such as American history teacher ([American history] teacher or American [history teacher]) before he can pronounce it correctly. The writing system does not mark surface structure except in certain gross ways such as by word spacing and punctuation marks. The beginning reader's task is apparently one of relating symbols to sounds at an age when such abilities as the ability to assign a surface structure may be quite different from those of sophisticated adults. Chomsky and Halle comment as follows on some of the problems:

There are many interesting questions that can be raised about the development of systems of underlying representation during the period of language acquisition. It is possible that this might be fairly slow. There is, for example, some evidence that children tend to hear much more phonetically than adults. There is no reason to jump to the conclusion that this is simply a matter of training and experience; it may very well have a maturational basis. Furthermore, much of the evidence relevant to the constructure of the underlying systems of representation may not be 
available in early stages of language acquisition. These are open questions, and it is pointless to speculate about them any further. They deserve careful empirical study, not only because of the fundamental importance of the question of "psychological reality" of linguistic constructs, but also for practical reasons; for example, with respect to the problem of the teaching of reading. 21

The comment is a most interesting one because if empirical evidence confirms the suspicion that Chomsky and Halle have, then it would tend to justify much of the approach taken to reading by Bloomfield and Fries. It would justify an approach which utilizes a taxonomic phonemic, or broad phonetic, level of representation and which relates such a level to orthographic patterns, an approach too which excludes work with derivational patterning in favor of work with sound-letter associations and which, by some kind of happy default, does not get itself involved with patterns of stress assignment in polysyllabic words, patterns which one can assume a six-year old already controls to a great extent by virtue of the fact that he is a native speaker.

It could well be that the basic problem a child has in learning to read is really one of learning the association between written symbols and surface rather than deep phonology. For example, he must learn that hatter:hater; petter:Peter; dinner:diner; comma:coma; and supper:super show a systematic spelling difference associated with a systematic surface phonological difference. In the terminology used by reading teachers he must learn that a double consonant indicates a "short" vowel and that a single consonant plus vowel indicates a "long" vowel. Even though the use of the letters $a, e, i, o$, and $u$ in the above words is "correct" in Chomsky and Halle's terms in spite of the very different phonetic realizations, the child's problem is one of cueing in to the visual task involved in decoding, a task which even the generativetransformationalists refer to as the problem of identifying the visual response. Likewise, with a set of words like metal, rebel, civil, Mongol, and cherub, it is important that the child have available to him a strategy for approaching these words so that he can attempt to pronounce them as metal or meetal, rebel or reeble, and so on. It helps him very little to be told that the spellings are the best ones for English because there are also English words like metallic, rebellion, civilian, Mongolian, and cherubic. A six-year old is even less likely to know these derivatives than the base forms and any knowledge about the "best" spellings for the second vowel in each word is more appropriate

${ }^{21}$ Chomsky and Halle, p. 50. 
to teaching him to spell than to read. Perhaps The Sound Pattern of English is a better book for those interested in teaching spelling than in teaching reading, tasks which appear to be rather different!

What the child basically needs in beginning reading is a set of strategies for decoding print. No one is really sure what strategies successful beginning readers do employ. There is reason to suspect that they do not use the strategies which teachers who believe in the various phonics approaches attempt to teach. These latter strategies, sometimes called phonic generalizations, have been severely attacked by linguists. However, a few of them seem to contain germs of truth, particularly recognizable after reading The Sound Pattern of English, as, for example, statements about final $e$ 's making preceding vowels "long," about an $i$ before gh having its "long" sound, about $c$ 's before $e$ 's or $i$ 's being "soft," and so on. But then such is likely to be the case. Phonics instruction cannot be all wrong-rather it shows evidence of considerable confusion in its general orientation and the need for a transfusion of linguistic insights, not euthanasia.

This discussion of the work of Bloomfield, Fries, Venezky, Chomsky, and Halle leads to certain conclusions. The first very obvious one is that some linguists do have an interest in applying their theoretical knowledge to the solution of practical problems. However, the second is that the proposed applications vary considerably and the results are sometimes contradictory. Linguists have different ideas about linguistics and about the nature of the problems to which linguistics might contribute a solution. Some linguists are also more definite in their proposals than others. It is possible to contrast the attempt by Fries at what appears to be a definitive attack on the reading problem to the extremely tentative suggestions put forward by Chomsky and Halle. Furthermore, the reading process itself is not an easy one to understand. Linguists have different notions about what language is, about how it may be described, about what its fundamental units are, about how these are related, and about what processes may operate. All these are linguistic matters quite properly and all have some relevance to understanding the reading process and teaching reading. But there are also non-linguistic matters which must be taken into account when one turns to problems in learning and teaching, and help must be sought from psychologists and educators as well as from linguists. The greatest need at present is for empirical work in which linguists, psychologists, and educators combine their insights in an attempt to improve our understanding of the reading process and the teaching of reading. 